\title{
Differential Behavior Between Isolated and Aggregated Rabbit Auricular Chondrocytes on Plastic Surfaces
}

\author{
V. Villar-Suárez, ${ }^{1}$ I. Calles-Venal, ${ }^{1}$ I. G. Bravo, ${ }^{2}$ J. G. Fernández-Álvarez, ${ }^{1}$ M. Fernández-Caso, ${ }^{1 *}$ and J. M. Villar-Lacilla ${ }^{1}$ \\ ${ }^{1}$ Departamento Biología Celular y Anatomía, Universidad de León, 24071 León, Spain \\ ${ }^{2}$ Departamento Bioquímica y Biología Molecular, Universidad de León, 24071 León, Spain
}

Received 19 November 2003; accepted 29 January 2004

\begin{abstract}
A knowledge of the behavior of chondrocytes in culture is relevant for tissue engineering. Chondrocytes dedifferentiate to a fibroblastlike phenotype on plastic surfaces. Dedifferentiation is reversible if these cells are then cultured in suspension. In this report a description is given of how when chondrocyte aggregates formed in suspension are next seeded on plastic, most of them attach as round or polygonal cells. This morphological differentiation, with synthesis of type II collagen, is stable for long culture periods. This simple method can be of use as a model for studies of chondrocyte behavior on plastic. The results indicate that in addition to culture conditions, such as cell isolation method or cell density, chondrocyte behavior on plastic depends on the presence of aggregates.
\end{abstract}

\section{INTRODUCTION}

Many studies [1,2,3], although with some exceptions [4], report that chondrocytes cultured on plastic lose their round shape and dedifferentiate to a fibroblast-like phenotype forming a monolayer of flattened cells. In suspension cultures, chondrocytes do not dedifferentiate, but demonstrate an inability to proliferate $[2,5,6,7,8,9,10$, $11,12,13,14]$.

To overcome the dedifferentiation of primary chondrocytes, or to achieve redifferentiation of previously proliferated chondrocytes, various culture models have been designed, including suspension cultures in spinner flasks [15], dishes coated with a nonadherent substrate $[5,16]$, high-density cultures $[17,18,19]$ or embedding in gels, whether collagen $[20,21]$, fibrin $[22,23,24]$, agarose $[2,7]$, or alginate $[3,11,13,25,26]$. Matrigel has also been used [27].

The study of dedifferentiation and redifferentiation requires a suitable culture model which supports such processes and permits the stable presence of differentiated or redifferentiated cells. However, primary chondrocytes on plastic undergo a dedifferentiation characterized by specific morphological changes from rounded and polygonal to fibroblast-shaped cells and a switch in the expression of cartilage-specific type II to type I collagen, among other metabolic changes $[28,29]$.

Various routes have been investigated with a view to maintaining differentiated chondrocytes in culture, including serum-free defined media, conditioned media, chondrocyte transformation, or chondrocyte immortal- ization with viral oncogenes [30]. Various chondrogenic cell lines from different sources, including primary chondrosarcomas, which reproduce some steps of the chondrocyte differentiation program have also been studied $[10,31]$.

However, in the way of study of these aspects is the poor phenotypical stability of chondrocytes in culture. The simple culture method described here, which permits considerable phenotypic stability, seems likely to prove helpful in overcoming these problems.

\section{MATERIALS AND METHODS}

\section{Chondrocyte isolation and culture}

Auricular cartilage was obtained from young New Zealand White rabbits aged one to three months. The perichondrium was carefully removed. Samples were cut into approximately $1 \mathrm{~mm}^{3}$ pieces. Dissociation was accomplished in the culture medium, without fetal calf serum, containing $2 \mathrm{mg} / \mathrm{mL}$ collagenase (type II, Sigma) and $0.1 \mathrm{mg} / \mathrm{mL}$ testicular hyaluronidase (type IV, Sigma) for $6-8$ hours at $37^{\circ} \mathrm{C}$. The resulting cell suspension was filtered through a nylon mesh, centrifuged at $300 \mathrm{Xg}$ for 5 minutes and the cells resuspended in the culture medium. Cells were cultured as primary cultures on plastic (adherent conditions) or in suspension (aggregating conditions).

In adherent conditions, cells were cultured in Dulbecco's modified Eagle's medium (Sigma-Aldrich, St Louis, Mo) with $10 \%$ fetal calf serum (Sigma), $0.5 \mathrm{~g} / \mathrm{L}$ 
glutamine (Sigma) and $0.5 \mathrm{~mL} / \mathrm{L}$ of an antibiotic antifungal solution (Sigma) in $25 \mathrm{~cm}^{2}$ tissue culture flasks at $37^{\circ} \mathrm{C}$ in a water-saturated atmosphere containing $5 \% \mathrm{CO}_{2}$. The medium was changed every $2-3$ days. The initial cell density was $10^{4}$ cells $/ \mathrm{cm}^{2}$. Cultured to confluence, cells were trypsinized and subcultured in a variable number of passages. Finally, they were seeded on Thermanox plastic coverslips (Nunc A/S, Roskilde, Denmark) on 24-well plates to facilitate later processing.

In aggregating conditions, chondrocyte aggregates were obtained by culturing cells in suspension on a nonadherent surface (2\% agar in PBS) in conditions as above. This method prevented cell flattening and they formed small aggregates that grew for about 7 days and then retained their size and characteristics for long periods. Aggregates were made from primary and monolayer subcultured chondrocytes with similar results.

Finally, aggregates cultured for 1 to 8 weeks in suspension were either seeded on plastic or added to confluent monolayers of proliferated and dedifferentiated chondrocytes.

\section{Light microscopy}

In addition to daily observations of cultures, cells were fixed with ethanol/acetic acid (99:1), dehydrated in ethanol and stained with hematoxylin-eosin. In other samples the extracellular matrix was stained with toluidine blue and alcian blue 8 GX (Sigma) at pH 1.0.

\section{Type II collagen detection}

Indirect immunofluorescence was performed by incubating fixed (as above) and washed cultures for 2 hours with primary antibodies against type II collagen (mouse monoclonal anti collagen II, Sigma, 1:1500) diluted in PBS. Then samples were washed twice in PBS and incubated for 1 hours with FITC-conjugated secondary antibodies raised in goat against mouse IGM (Sigma) previously diluted 1:50. Washed twice in PBS, samples were mounted with a non-fluorescing mounting medium (Sigma). Control experiments were carried out in auricular cartilage and in dedifferentiated chondrocyte monolayer cultures by repeating the processing with or without primary antibody.

\section{RESULTS}

This paper describes different cell shapes. The following general terms will be used: round cells (spherical cells without cell processes), polygonal cells (cells not totally spherical, sometimes with short cell processes), fibroblastic cells (enlarged and flattened cells with long cell processes) and polymorphic cells (cells of greater dimensions, very flattened, with very long cell processes and very irregular contours).

\section{Cells cultured on plastic}

Auricular chondrocytes lost their characteristic round shape and grew with a fibroblast-like phenotype on plas- tic (Figure 1a). Dedifferentiated chondrocytes showed a typical spindle-shaped morphology with long filopodia. No special cell rearrangements occurred, nor were differentiated subpopulations present. Dedifferentiated cells showed an easy substrate attachment and a fast proliferation which formed confluent monolayers of fibroblastic cells. Neither round nor polygonal cells were observed in considerable quantity. Subsequent subcultures maintained this behavior, but a change in cell shape progressively took place. This consisted of the appearance of very large and shortly flattened cells, termed polymorphic cells (Figure 1b) owing to their irregular shape. Indirect immunofluorescence of type II collagen showed no labelling (Figure 1c).

\section{Cells cultured in suspension}

When primary or subcultured chondrocytes were cultured in suspension, cell flattening proved impossible and many spherical aggregates of round cells appeared floating in the culture medium (Figure 1d). They grew for about 7 days, and progressively developed a dense alcian-bluepositive pericellular matrix. Aggregates were very stable in culture; when cultured for 1 to 8 weeks, no appreciable changes occurred in their appearance, except for a flattening of their peripheral cells which recalled the perichondrium in vivo (Figure 1e). The central cells were round, their pericellular matrix showed an affinity for alcian blue and toluidine blue metachromatic staining and their synthesis of type II collagen was intense (Figure 2a) like that of differentiated or redifferentiated chondrocytes. These characteristics coincide very well with those described by Stewart et al [32] in equine articular chondrocytes and Estrada et al [33] in porcine epiphyseal chondrocytes.

\section{Aggregates cultured on plastic}

Aggregates of primary or subcultured chondrocytes transferred onto a plastic surface slowly adhered to it. Thereafter, peripheral cells expanded from their borders, growing radially and forming structures very similar to the chondrogenic plates of embryonic culture models (Figure 2b). Peripheral flattened cells were initially fibroblastic in shape, but they were progressively transformed into polymorphic cells, very irregular cells of greater dimensions with a high content in vacuoles. In the centers of the plates, very numerous round cells, which sometimes formed cartilaginous nodules, were surrounded by polygonal cells (Figure 2c). With regard to monolayer cultures, the cell proliferation rate apparently decreased, because cells did not cover all the available plastic surface. Many cells remained in suspension, floating in the culture medium, suggesting a decrease in substrate adhesion.

Aggregates previously kept in suspension for 1 to 8 weeks were cultured on plastic. Aggregates cultured for 1 week formed chondrogenic plates with many round and polygonal cells and few fibroblastic and polymorphic cells. Round and polygonal chondrocytes were very stable in their shape and they did not change their behavior over 


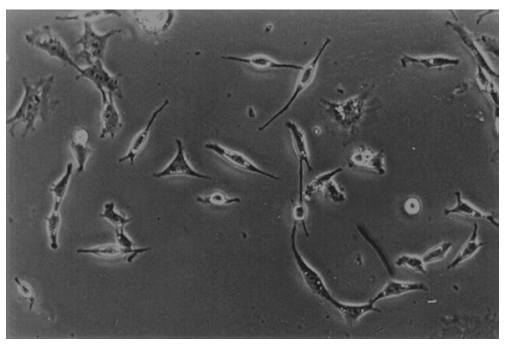

(a)

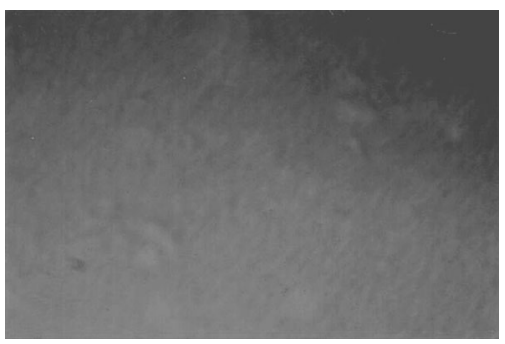

(c)

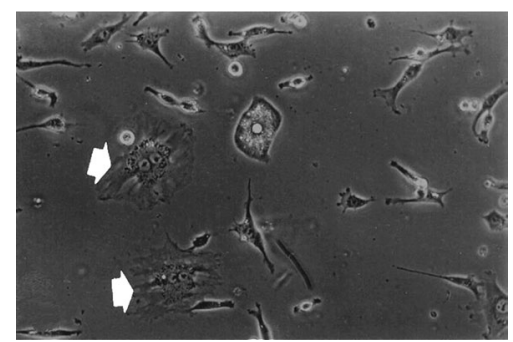

(b)

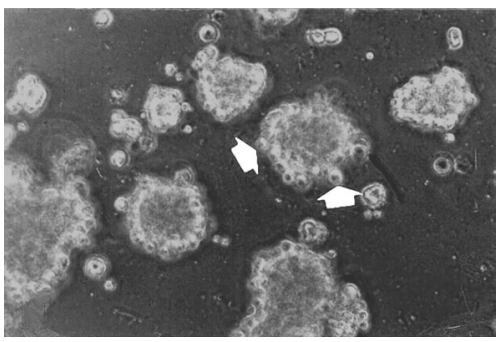

(d)

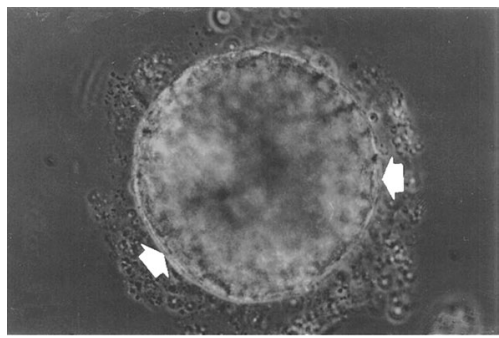

(e)

FIGURE 1. (a) Dedifferentiated chondrocytes with a fibroblast-like phenotype in primary culture on plastic, OM 50 X. (b) Subcultured chondrocytes on plastic show the appearance of some polymorphic cells (arrow), OM $50 \mathrm{X}$. (c) Immunofluorescence of type II collagen shows a negligible labelling in confluent monolayers, even in primary cell cultures, OM 25 X. (d) Dedifferentiated chondrocytes cultured in suspension for one week form aggregates of round cells; note the round shape of peripheral cells (arrow), OM $50 \mathrm{X}$. (e) Aggregates cultured in suspension for more than one week show peripheral perichondrium-like cell flattening (arrow), OM $50 \mathrm{X}$.

long culture periods of more than three months. These cells developed a refractile pericellular matrix. Round cells frequently detached from the plastic, remaining in suspension.

When the time that aggregates had been in suspension increased, the relative numbers of round and polygonal cells decreased, and fibroblastic and polymorphic cells were more abundant. Aggregates cultured for 7 and 8 weeks in suspension produced only polymorphic cells on plastic. It is interesting to note that during this time a perichondrial-like layer progressively developed and that fibroblastic and polymorphic cells, always peripheral, were able to derive from this layer.

In cultures with round and polygonal cells, type II collagen was extensively produced (Figure $2 \mathrm{~d}$ ), but in cul- tures with a great number of polymorphic cells the synthesis of type II collagen was negligible.

\section{Addition of aggregates to dedifferentiated monolayer cultures}

To ascertain whether the differentiation state of the aggregates has some effect on dedifferentiated chondrocytes, aggregates cultured for 1 week in suspension were added to confluent monolayers of subcultured chondrocytes. The results were similar to those described in the previous section, with the presence of many chondrogenic plates (Figures 2e, 2f). Fibroblastic cells were very scarce. Chondrogenic plates were typically made up of a central aggregate surrounded by polygonal cells and some polymorphic cells peripherally. This arrangement coincides with 


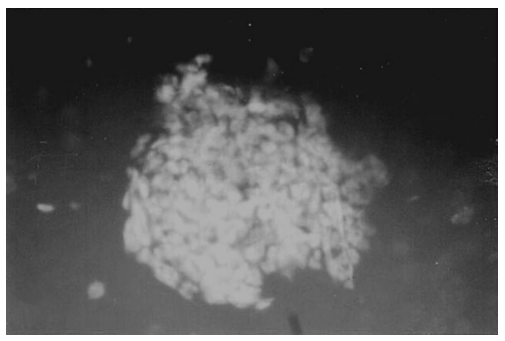

(a)

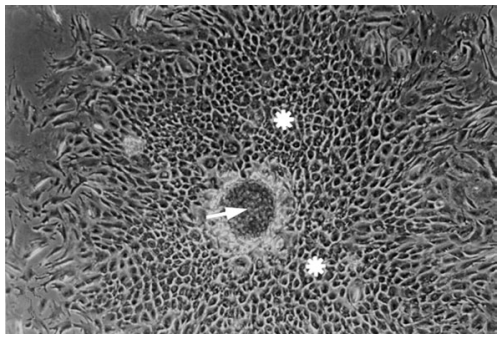

(c)

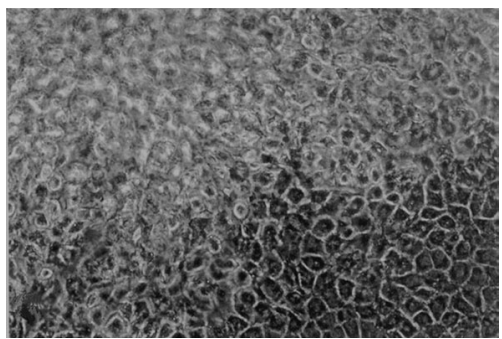

(e)

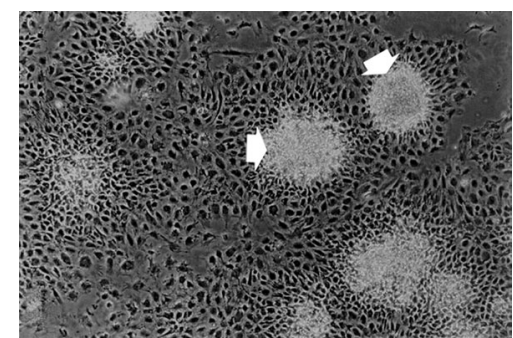

(b)

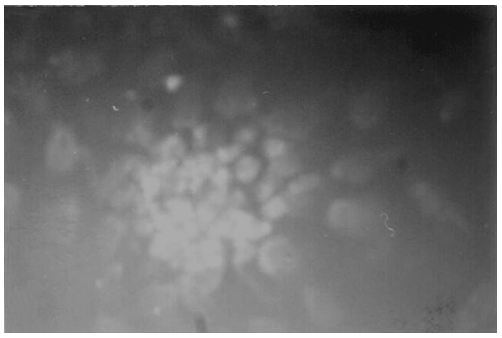

(d)

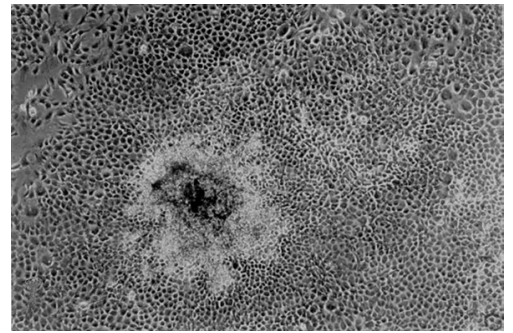

(f)

Figure 2. (a) Immunofluorescence of type II collagen shows intense labelling in aggregates cultured in suspension, OM 25 X. (b) Aggregates transferred onto plastic form stable plates of differentiated chondrocytes with cartilaginous nodules (arrow), OM $25 \mathrm{X}$. (c) A cartilaginous nodule with central round cells (arrow), intermediate polygonal cells (asterisk), and peripheral fibroblastic and polymorphic cells, OM 25 X. (d) Type II collagen is extensively produced by round and polygonal cells, OM 25 X. (e) Addition of aggregates to dedifferentiated monolayer cultures; note the extensive presence of round cells surrounded by extracellular matrix (upper) and polygonal cells surrounded by a refractile matrix (lower), OM 50 X. (f) Addition of aggregates to dedifferentiated monolayer cultures; positive alcian blue staining, OM $25 \mathrm{X}$.

what was reported by Ishizeki et al $[34,35]$ for the culture of Meckel's cartilage chondrocytes of fetal mice. The synthesis of type II collagen was extensive and the proteoglycan staining was positive (Figure $2 \mathrm{f}$ ).

\section{DISCUSSION}

Phenotypically stable chondrocytes are needed for many experimental purposes. However, the differentiated phenotype is unstable and difficult to maintain in culture. Chondrocytes undergo a rapid change in phenotype, termed dedifferentiation, when isolated from cartilage tissue and cultured on tissue culture plastic. These dedifferentiated cells redifferentiate in suspension cul- ture and the synthesis of cartilage extracellular matrix molecules reinitiates, but cell proliferation decreases. The control of chondrocyte proliferation, dedifferentiation, and redifferentiation is crucial for modern tissue engineering techniques.

\section{Cells cultured on plastic}

As occurs with other chondrocyte types, the culture of auricular chondrocytes on plastic produces a dedifferentiation which turns these spherical cells into fibroblastlike cells. These dedifferentiated cells proliferate until they form a confluent monolayer. Metabolic changes in this dedifferentiated state include a changeover from type II collagen to type I collagen synthesis $[14,28,32]$. 


\section{Cells cultured in suspension}

Chondrocytes have previously been cultures in suspension on agarose. Goldring [30] describes a method similar to the procedure reported here, and stated that cells first form large clumps, then these began to break up after 7-10 days, becoming a single cell suspension. No such breakup was observed in the current work; apart from different cell sources, this seems likely to be the outcome due of the agarose concentration in Goldring's method (1\%) in comparison with the agar gel used here $(2 \%)$.

The formation of similar aggregates in suspension cultures has been reported by Castagnola et al [5] in chick embryo tibia chondrocytes on agarose-coated dishes, by Shakibaei and De Souza [8] in mesenchymal cells from mouse limb buds cultured in alginate, by Lunstrum et al [10] in a rat mesenchymal cell line on bacteriological dishes, by Gagne et al [11] with human articular chondrocytes in an alginate suspension culture system, by Stewart et al [32] with equine articular chondrocytes, and by Estrada et al [33] with porcine epiphyseal chondrocytes. As in the present study, in all cases these aggregates showed phenotypic stability and the expression of some markers of chondrocyte differentiation. However, in most of these works, mainly with embryo chondrocytes, investigation ceased at this point.

\section{Aggregates cultured on plastic}

Various methods to obtain pure chondrocyte populations using embryo cells have been described. Castagnola et al [5] report that chondrocytes from chick embryo tibiae cultured in suspension in agarose-coated dishes resumed the chondrocyte phenotype and their differentiation to hypertrophy continued; in 3-4 weeks, a nearly homogeneous population of single isolated hypertrophic chondrocytes was obtained. Shakibaei and De Souza [8] report that when isolated mesenchymal cells from mouse limb buds are cultured in alginate, only a subpopulation of differentiated chondrocytes was selected, showing a stable phenotype until the end of the culture; fibroblast-like cells became necrotic in these conditions. By dissolving alginate, cells which maintain their pericellular matrix can be cultivated in micromass to give a pure chondrocyte population. A similar method has been applied to redifferentiate adult articular chondrocytes [19].

This study describes a similar method but using auricular chondrocytes. We also report that aggregates in suspension can be transferred to plastic surfaces resulting in a considerable phenotypical stability. The results suggest that the maintenance of a differentiated phenotype on plastic occurs when chondrocytes have their pericellular matrix. We propose that cells deprived of their pericellular matrix by enzyme digestion, such as dissociated cells, attach to plastic in a dedifferentiated form. However, cells that retain their original pericellular matrix or that have reconstructed it in suspension attach to plastic with a differentiated phenotype. By other methods, Stewart et al [32] also conclude this relationship between pericellular matrix and the stable expression of the articular chondrocyte phenotype in suspension culture. Indeed, the pericellular matrix is the natural substrate of chondrocytes in vivo. Therefore, the influence of the pericellular matrix on the differentiation state of the chondrocytes hence seems to be of major importance [36].

\section{Addition of aggregates to dedifferentiated monolayer cultures}

The addition of aggregates cultured for 1 week in suspension to confluent monolayers of dedifferentiated chondrocytes produces many chondrogenic plates and cell shape became round or polygonal. The cells synthesize type II collagen and proteoglycans. Shakibaei and De Souza [8] report that mesenchymal limb bud cells cultured in alginate were selected and, while attached to their pericellular matrix, followed a chondrocyte pathway of differentiation. In aggregates of auricular chondrocytes in the present study, the pericellular matrix is visible around the cells. These results suggest that the presence of some differentiated chondrocytes surrounded by their pericellular matrix influences the differentiation state of other chondrocytes on plastic surfaces.

\section{Chondrocyte dedifferentiation and redifferentiation}

The maintenance of the differentiated phenotype on plastic seems to depend on the presence of some cells with their pericellular matrix. Chen et al's experiments [36] demonstrate similar behavior in chick embryo growth plate chondrocytes. Chondrocytes in organ culture, and thus with their own extracellular matrix environment, maintain their state and progress in the differentiation programme as in vivo. However, these same cells when dissociated, without extracellular matrix, and cultured in pellets, regressed in the differentiation program.

This interpretation may explain various behaviors observed in adult chondrocyte culture. Dedifferentiation on plastic would occur because cells lack their pericellular matrix, owing to the dissociation process. However, chondrocyte aggregates, with newly-formed pericellular matrix, can grow on plastic maintaining a certain differentiation. Pellet or micromass cultures obviously promote the aggregation and redifferentiation of cells in a similar manner. It is also known that dedifferentiation is attenuated by culturing chondrocytes at high density.

Patti et al [4] have reported surprising results working with adult articular chondrocytes cultured on plastic. They report that these cells in monolayer culture retained their differentiated characteristics for more than five months, including the ability to produce cartilagespecific molecules. These results seem to contradict many other studies. However, they report that as an outcome of the dissociation method used "some single or aggregated chondrocytes suspended in the digest were surrounded by remnants of territorial matrix." Hence, it seems probable that owing to incomplete dissociation, such aggregates 
included in the cultures were responsible for the differentiation that these authors reported.

Consequently, a conclusion of this study is that, in addition to other known culture conditions such as cell density, chondrocyte behavior on plastic is strongly dependent on the factors outlined above. Therefore, the presence of cell aggregates should be kept in mind in chondrocyte culture studies and in tissue engineering techniques.

As an example of their potential, de Chalain et al [37] reported the production of a large amount of elastic cartilage from porcine and human chondrocytes when enzymatically isolated chondrocytes were agitated in suspension, forming chondron-like aggregates, which were further embedded in alginate and type I collagen. By implanting these constructs in nude mice, neocartilages were obtained closely resembling native auricular cartilage, both phenotypically and in matrix composition. We think that these aggregates, similar to those in the current study, might be an alternative to the use of isolated chondrocytes in both chondrocyte transplant and tissue engineering techniques. It is hoped that this report will improve the knowledge of why this success was reached.

However, further investigations focused on the regulatory mechanisms using molecular biology techniques are needed to understand these processes and their practical possibilities.

\section{ACKNOWLEDGMENTS}

This investigation was supported by a Grant from the Junta de Castilla y León (LE 04/00F). I. G. Bravo holds a Fellowship from the Ramón Areces Foundation.

\section{REFERENCES}

[1] von der Mark K, Gauss V, von der Mark H, Muller P. Relationship between cell shape and type of collagen synthesized as chondrocytes lose their cartilage phenotype in culture. Nature. 1977;267(5611):531-532.

[2] Benya PD, Shaffer JD. Dedifferentiated chondrocytes reexpress the differentiated collagen phenotype when cultured in agarose gels. Cell. 1982;30(1):215224.

[3] Bonaventure J, Kadhom N, Cohen-Solal L, Ng KH, Bourguignon J, Lasselin C, Freisinger P. Reexpression of cartilage-specific genes by dedifferentiated human articular chondrocytes cultured in alginate beads. Exp Cell Res. 1994;212(1):97-104.

[4] Patti AM, Gabriele A, Della Rocca C. Human chondrocyte cell lines from articular cartilage of metatarsal phalangeal joints. Tissue Cell. 1999;31(6): 550-554.

[5] Castagnola P, Moro G, Descalzi-Cancedda F, Cancedda R. Type X collagen synthesis during in vitro development of chick embryo tibial chondrocytes. $J$ Cell Biol. 1986;102(6):2310-2317.

[6] Watt FM, Dudhia J. Prolonged expression of dif- ferentiated phenotype by chondrocytes cultured at low density on a composite substrate of collagen and agarose that restricts cell spreading. Differentiation. 1988;38(2):140-147.

[7] Aulthouse AL, Beck M, Griffey E, Sanford J, Arden K, Machado MA, Horton WA. Expression of the human chondrocyte phenotype in vitro. Vitro Cell Dev Biol. 1989;25(7):659-668.

[8] Shakibaei M, De Souza P. Differentiation of mesenchymal limb bud cells to chondrocytes in alginate beads. Cell Biol Int. 1997;21(2):75-86.

[9] Binette F, McQuaid DP, Haudenschild DR, Yaeger PC, McPherson JM, Tubo R. Expression of a stable articular cartilage phenotype without evidence of hypertrophy by adult human articular chondrocytes in vitro. J Orthop Res. 1998;16(2):207-216.

[10] Lunstrum GP, Keene DR, Weksler NB, Cho Y-J, Cornwall M, Horton WA. Chondrocyte differentiation in a rat mesenchymal cell line. J Histochem Cytochem. 1999;47(1):1-6.

[11] Gagne TA, Chappell-Afonso K, Johnson JL, et al. Enhanced proliferation and differentiation of human articular chondrocytes when seeded at low cell densities in alginate in vitro. J Orthop Res. 2000;18(6): 882-890.

[12] Haudenschild DR, McPherson JM, Tubo R, Binette F. Differential expression of multiple genes during articular chondrocyte redifferentiation. Anat Rec. 2001;263(1):91-98.

[13] van Osch GJ, van der Veen SW, VerwoerdVerhoef HL. In vitro redifferentiation of cultureexpanded rabbit and human auricular chondrocytes for cartilage reconstruction. Plast Reconstr Surg. 2001;107(2):433-440.

[14] Yoon YM, Kim SJ, Oh CD, et al. Maintenance of differentiated phenotype of articular chondrocytes by protein kinase $\mathrm{C}$ and extracellular signal-regulated protein kinase. J Biol Chem. 2002;277(10):84128420 .

[15] Norby DP, Malemud CJ, Sokoloff L. Differences in the collagen types synthesized by lapine articular chondrocytes in spinner and monolayer culture. Arthritis Rheum. 1977;20(2):709-716.

[16] Glowacki J, Trepman E, Folkman J. Cell shape and phenotypic expression in chondrocytes. Proc Soc Exp Biol Med. 1983;172(1):93-98.

[17] Kuettner KE, Pauli BU, Gall G, Memoli VA, Schenk RK. Synthesis of cartilage matrix by mammalian chondrocytes in vitro. I. Isolation, culture characteristics, and morphology. J Cell Biol. 1982;93(3):743750.

[18] Bassleer C, Gysen P, Foidart JM, Bassleer R, Franchimont P. Human chondrocytes in tridimensional culture. Vitro Cell Dev Biol. 1986;22(3):113-119.

[19] Schulze-Tanzil G, de Souza P, Villegas Castrejon H, John T, Merker H-J, Scheid A, Shakibaei M. Redifferentiation of dedifferentiated human 
chondrocytes in high-density cultures. Cell Tissue Res. 2002;308(3):371-379.

[20] Gibson GJ, Schor SL, Grant ME. Effects of matrix macromolecules on chondrocyte gene expression: synthesis of a low molecular weight collagen species by cells cultured within collagen gels. J Cell Biol. 1982;93(3):767-774.

[21] Schuman L, Buma P, Versleyen D, et al. Chondrocyte behaviour within different types of collagen gel in vitro. Biomaterials. 1995;16(10):809-814.

[22] Homminga GN, Buma P, Koot HW, van der Kraan PM, van den Berg WB. Chondrocyte behavior in fibrin glue in vitro. Acta Orthop Scand. 1993;64(4):441445.

[23] Haisch A, Schultz O, Perka C, Jahnke V, Burmester GR, Sittinger M. Tissue engineering of human cartilage tissue for reconstructive surgery using biocompatible resorbable fibrin gel and polymer carriers. HNO. 1996;44(11):624-629.

[24] Fortier LA, Brofman PJ, Nixon AJ, Mohammed HO. Disparate chondrocyte metabolism in threedimensional fibrin cultures derived from autogenous or commercially manufactured fibrinogen. Am $J$ Vet Res. 1998;59(4):514-520.

[25] Guo JF, Jourdian GW, MacCallum DK. Culture and growth characteristics of chondrocytes encapsulated in alginate beads. Connect Tissue Res. 1989;19(24):277-297.

[26] Hauselmann HJ, Aydelotte MB, Schumacher BL, Kuettner KE, Gitelis SH, Thonar EJ. Synthesis and turnover of proteoglycans by human and bovine adult articular chondrocytes cultured in alginate beads. Matrix. 1992;12(2):116-129.

[27] Vukicevic S, Kleinman HK, Luyten FP, Roberts AB, Roche NS, Reddi AH. Identification of multiple active growth factors in basement membrane Matrigel suggests caution in interpretation of cellular activity related to extracellular matrix components. Exp Cell Res. 1992;202(1):1-8.

[28] Zaucke F, Dinser R, Maurer P, Paulsson M. Cartilage oligomeric matrix protein (COMP) and collagen IX are sensitive markers for the differentiation state of articular primary chondrocytes. Biochem J. 2001;358(pt 1):17-24.

[29] Schnabel M, Marlovits S, Eckhoff G, Fichtel I, Gotzen L, Vécsei V, Schlegel J. Dedifferentiationassociated changes in morphology and gene expression in primary human articular chondrocytes in cell culture. Osteoarthritis Cartilage. 2002;10(1):62-70.

[30] Goldring MB. Human chondrocyte cultures as models of cartilage-specific gene regulation. In: Jones GE, ed. Methods in Molecular Biology: Human Cell Culture Protocols. Totowa, NJ: Humana Press Inc; 1996:217-231.

[31] Grigoriadis AE, Heersche JNM, Aubin JE. Analysis of chondroprogenitor frequency and cartilage differentiation in a novel family of clonal chondrogenic rat cell lines. Differentiation. 1996;60(5):299-307.
[32] Stewart MC, Saunders KM, Burton-Wurster N, Macleod JN. Phenotypic stability of articular chondrocytes in vitro: the effects of culture models, bone morphogenetic protein 2, and serum supplementation. J Bone Miner Res. 2000;15(1):166-174.

[33] Estrada LE, Dodge GR, Richardson DW, Farole A, Jiménez SA. Characterization of a biomaterial with cartilage-like properties expressing type $\mathrm{X}$ collagen generated in vitro using neonatal porcine articular and growth plate chondrocytes. Osteoarthritis Cartilage. 2001;9(2):169-177.

[34] Ishizeki K, Chida T, Yamamoto H, Nawa T. Light and electron microscopy of stage-specific features of the transdifferentiation of mouse Meckel's cartilage chondrocytes in vitro. Acta Anat (Basel). 1996;157(1):1-10.

[35] Ishizeki K, Takigawa M, Nawa T, Suzuki F. Mouse Meckel's cartilage chondrocytes evoke bone-like matrix and further transform into osteocyte-like cells in culture. Anat Rec. 1996;245(1):25-35.

[36] Chen Q, Johnson DM, Haudenschild DR, Goetinck PF. Progression and recapitulation of the chondrocyte differentiation program: cartilage matrix protein is a marker for cartilage maturation. Dev Biol. 1995;172(1):293-306.

[37] de Chalain T, Phillips JH, Hinek A. Bioengineering of elastic cartilage with aggregated porcine and human auricular chondrocytes and hydrogels containing alginate, collagen, and kappa-elastin. J Biomed Mater Res. 1999;44(3):280-288.

\footnotetext{
* Corresponding author.

E-mail: dbcmfc@unileon.es

Fax: + 34987291 276; Tel: + 34987291272
} 

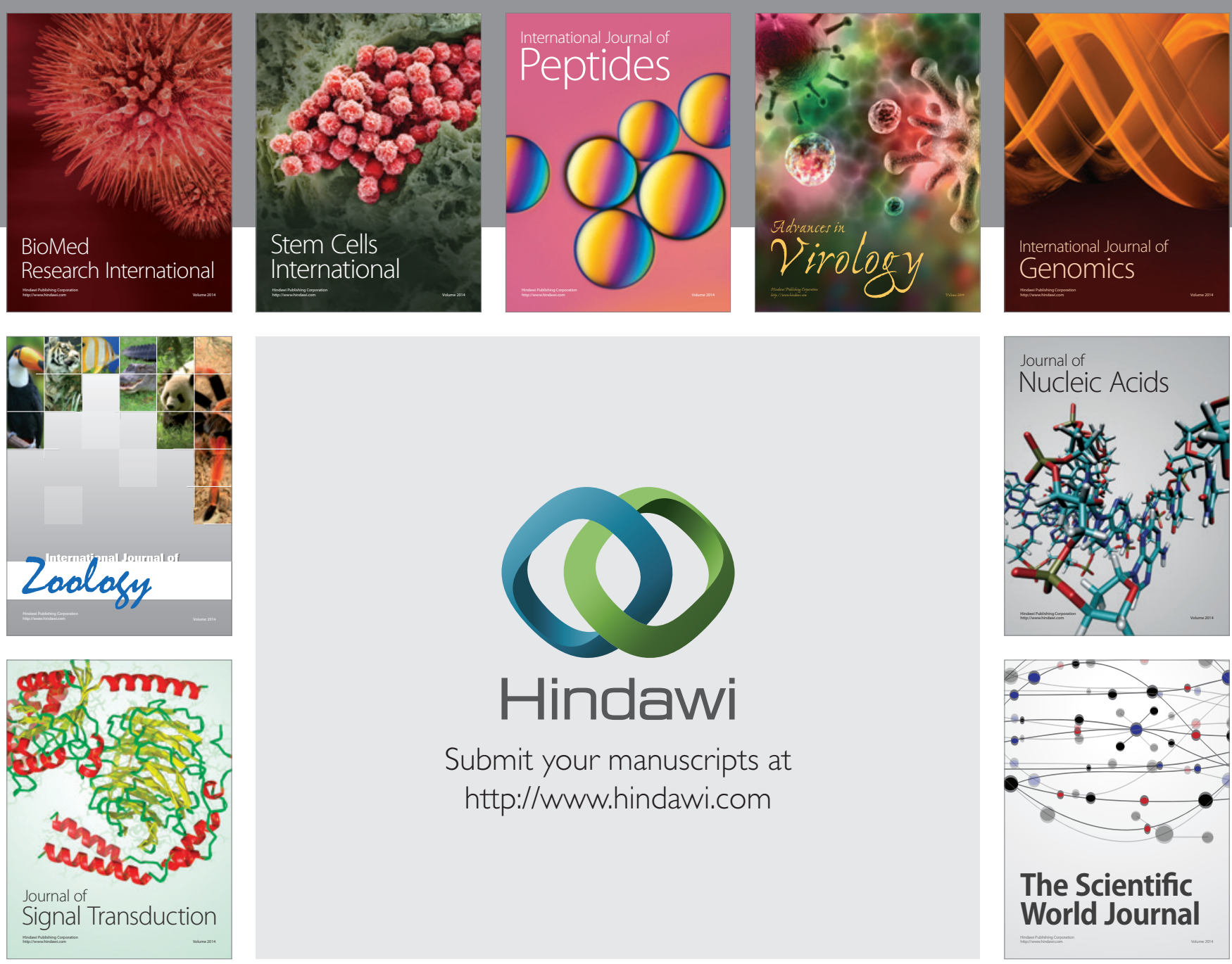

Submit your manuscripts at

http://www.hindawi.com
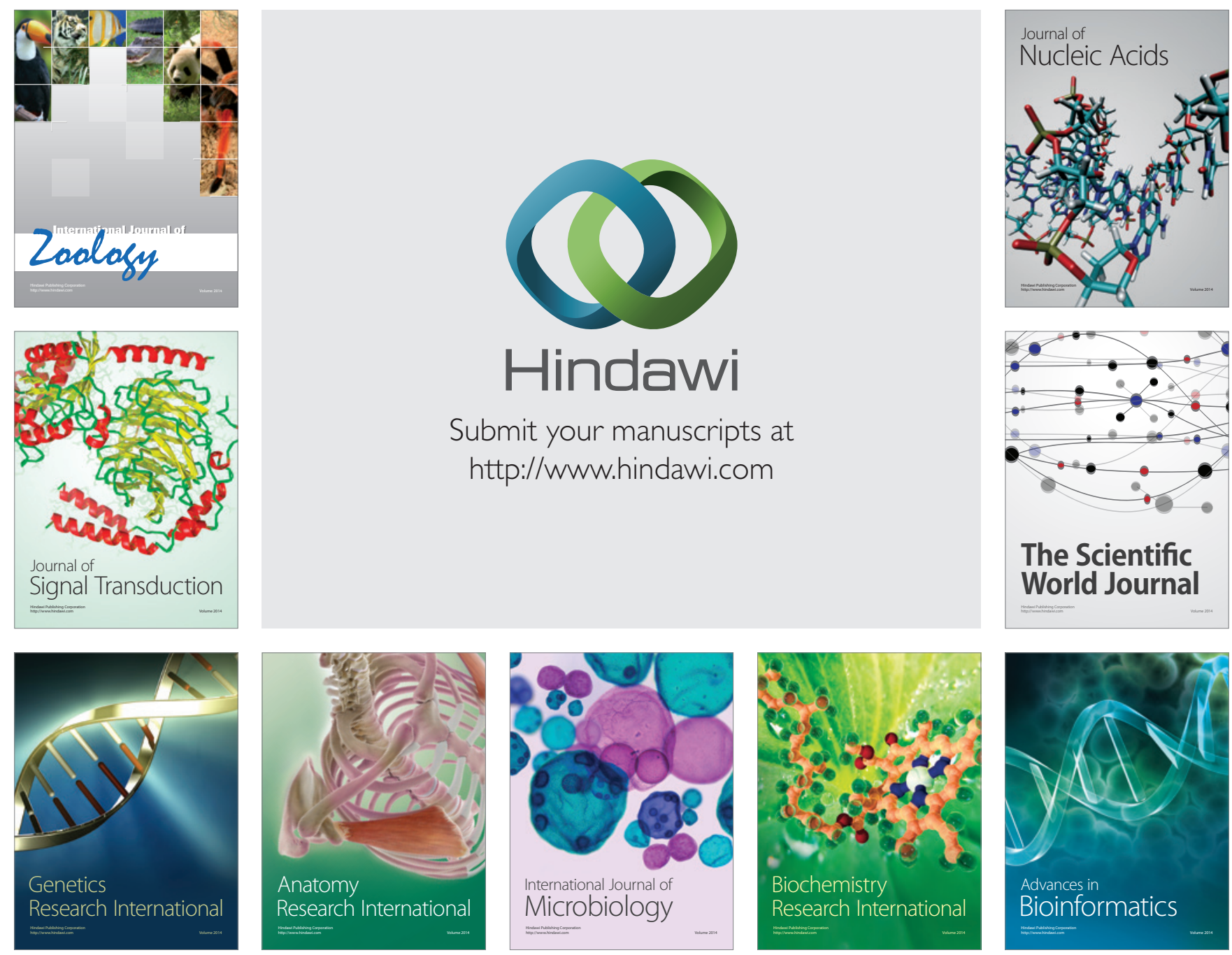

The Scientific World Journal
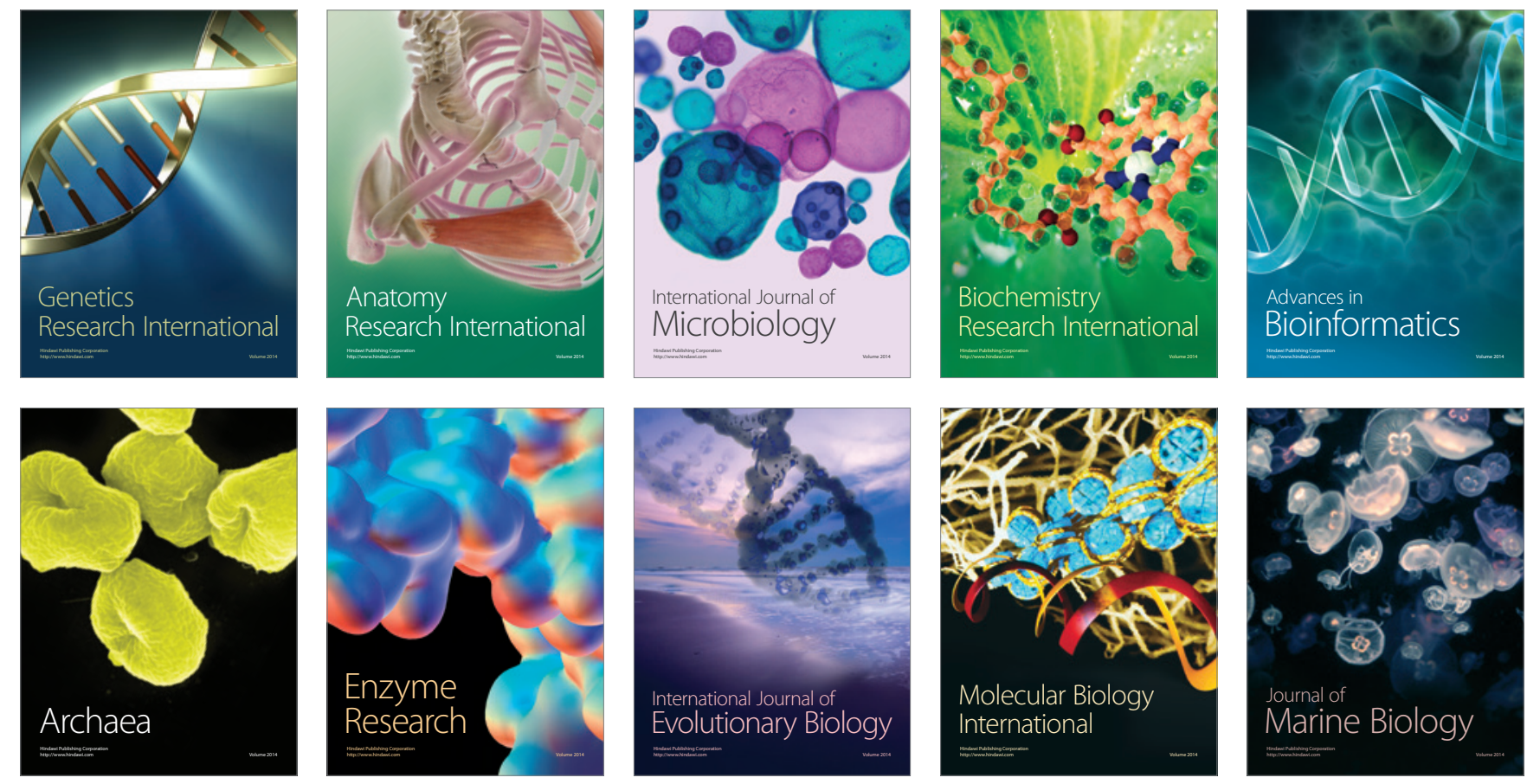